\title{
Turning back to the Analysis of Extraterrestrial Objects
}

DOI: $10.1134 / \mathrm{S} 1061934810090017$

Methods of chemical analysis allow us to gain an increasing amount of data on the composition of extraterrestrial objects. The most often used methods are spectroscopy, including $\mathrm{X}$-ray spectrometry; mass spectrometry; and nuclear physics methods, often in their remote versions. A review of recent achievements in this field was given in four chapters of the monograph Vnelaboratornyi khimicheskii analiz (Extralaboratory Chemical Analysis) [1]. Here, I will restrict myself to some examples that have not been reflected in this monograph.

The simplest amino acid glycine was detected by spectrochemical methods in samples collected in the Wild 2 comet by the Stardust space vehicle and delivered to Earth [2]. We have previously noted signs of the presence of some amino acids in the interstellar space (data of remote spectroscopic studies), and now direct evidence has been obtained. Amino acids are building blocks of proteins, and this fact is of great importance for the discussion of the problems of the origin of life. In this connection, let me also note the detection of methane and also water ice on Mars [1, 3], also by nuclear physics methods.

Recently, more extensive information about the chemical composition of the comet substance has also been accumulated [4]. In 2005, the space vehicle Deep Impact invaded the head of the Tempel 1 comet; the vehicle was equipped with a spectrometer that recorded infrared spectra of substances forming the head of the comet. The assignment of these spectra allowed the researchers to detect the presence of olivine, clays, polynuclear aromatic organic compounds, water ice, amorphous carbon, sulfides, and other substances.
Interesting information was obtained about Saturn's satellite, Titan, which is similar to Earth. It has many liquids, but these are probably neither water nor liquid methane: the temperature on Titan is minus 180 degrees centigrade. The surface of this cosmic body bears ammonia deposits. The dense Titan's atmosphere consists of methane, nitrogen, and ammonia. All these results could be obtained mainly as a result of remote investigations carried out automatically by the Cassini-Guigens cosmic station.

IR spectroscopic studies have detected molecules of polynuclear aromatic hydrocarbons, for example protonated naphthalene, in the interstellar space [5].

A separate, and important, branch of chemical analysis is the control of the human environment of cosmonauts inside the space craft. The tendency to the miniaturization of analyzers used for this purpose has led to the development of instruments based on microfluid technology (microchips) [6].

\section{REFERENCES}

1. Vnelaboratornyi khimicheskii analiz (Seriya Problemy analiticheskoi khimii) (Extralaboratory Chemical Analysis (Series: Problems of Analytical Chemistry, vol. 13), Zolotov, Yu.A., Ed., Moscow: Nauka, 2010.

2. Chem. Eng. News, 2009, August 24, p. 32.

3. Wilson, E., Chem. Eng. News, 2009, January 19, p. 11.

4. Jacoby, M., Chem. Eng. News, 2006, July 17, p. 7.

5. Astrophys. J., 2009, vol. 702, p. 301.

6. Kern, P., Bioword Europe, 2007, no. 1, p. 40.

Yu. A. Zolotov 